\title{
Regeneration of the larval sea star nervous system by wounding induced respecification to the sox2 lineage
}

Minyan Zheng ${ }^{\dagger}$ Olga Zueva, Veronica F. Hinman*

Affiliations:

Department of Biological Sciences, Carnegie Mellon University, Pittsburgh. PA. 15213 USA.

*corresponding author. veronica@cmu.edu

†Present address: Department of Genetics, Harvard Medical School, Boston, Massachusetts 02115, USA 


\section{Abstract}

The ability to restore lost body parts following traumatic injury is a fascinating area of biology that challenges current understanding of the ontogeny of differentiation. The origin of new cells needed to regenerate lost tissue, and whether they are pluripotent stem cells, tissue-specific stem cells or have de- or trans- differentiated, remains one of the most important open questions in regeneration. Additionally, it is not clearly known whether developmental gene regulatory networks (GRNs) are reused to direct specification in these cells or whether regeneration specific networks are deployed. Echinoderms, including sea stars, have extensive ability for regeneration and have therefore been the subject of many thorough studies on the ultrastructural and molecular properties of cells needed for regeneration. However, the technologies for obtaining transgenic echinoderms are limited and tracking cells involved in regeneration, and thus identifying the cellular sources and potencies has proven challenging. In this study we develop new transgenic tools for cell tracking in the regenerating bipinnaria larva of the sea star Patira minaita. We show that the larval serotonergic nervous system can regenerate following decapitation. Using a BAC-transgenesis approach with photoconvertible fluorescent proteins, we show that expression of the pan ectodermal marker, sox2, is induced in previously sox 2 minus cells at the wound site, even when cell division is inhibited. sox $2+$ cells give rise to new sox4+ neural precursors that then proceed along an embryonic neurogenesis pathway to reform the anterior nervous systems. sox2+ cells contribute to only neural and ectoderm lineages, indicating that these progenitors maintain their normal, embryonic lineage restriction. This indicates that sea star larval regeneration uses a combination of existing lineage restricted stem cells, as well as respecification of cells into neural lineages, and at least partial reuse of developmental GRNs to regenerate their nervous system. 


\section{Introduction}

Regeneration is a fascinating phenomena that challenges the tenet of an irreversible, directional ontogeny. Decades of research have provided extensive understanding of how embryonic cells acquire their fate through the action of GRNs and the sequential turning on, and off, of regulatory genes. During embryogenesis these developmental GRNs start from a very particular cell type, the single-celled zygote, while in regeneration another source of multi-, or toti-potent cells must be the source of cells for regeneration. The source of the cells, their molecular state and how, or even whether, developmental GRNs are re-established in these cells are open questions. This knowledge is needed as a prerequisite for understanding the molecular mechanisms of regeneration. Furthermore, an understanding of whether any processes are homologous or if there are taxon-specific mechanisms that are related to the ability for extensive or limited regeneration awaits sufficient sampling across the metazoa.

The deuterostomes, i.e. vertebrates, invertebrate chordates, echinoderms and hemichordates, are an especially important system to study from the standpoint of regeneration. The vertebrates, with some few exceptions, have limited capacity for regeneration that is usually restricted to specific cells, tissues and organs (Rodriguez and Kang, 2020; Tanaka and Reddien, 2011). The emerging evidence points to the use of tissue-specific stem cells and corresponding specific niches as a cellular source for regeneration (Kragl et al., 2009). Echinoderms on the other hand have an impressive ability for extensive whole body regeneration found in most species of the phylum (Ferrario et al., 2020). For this reason, there has been extensive research into the mechanisms of regeneration in many species of echinoderms (Ferrario et al., 2020; Kondo and Akasaka, 2010; Dupont and Thorndyke, 2007; Piovani et al., 2021; Vickery et al., 2001; García-Arrarás et al., 2018; Mashanov and Zueva, 2019; Mashanov et al., 2020). For example, molecular and ultrastructural studies in brittle star arm regeneration point to use of adjacent epithelial cells to differentiate into sclerocytes needed for arm skeleton regeneration, recapitulating, at least in part, a development program (Piovani et al., 2021). Comprehensive studies in the regeneration of radial nerve chords in sea cucumbers also point to the use of radial glial dedifferentiation in nervous system regeneration (Mashanov and Zueva, 2019; Mashanov et al., 2015a, 2017). The emerging consensus from these and other studies is that echinoderms rely extensively on wound-adjacent dedifferentiation for regenerating lost tissues (Ferrario et al., 2020; Mashanov and Zueva, 2019). Conversely, 
expression of stem-cell marker genes have been identified as possible cell sources in some species (Mashanov et al., 2015b; Reinardy et al., 2015). Whether echinoderms and vertebrates use similar cellular sources and mechanisms for regeneration (Zhang et al., 2003; Joven and Simon, 2018) is important for untangling whether these mechanisms are causative of whole-body versus limited regeneration potential. Understanding these processes in naturally regenerating contexts has important implications for improved translational applications of induced pluripotent stem cells and other stem cell therapies.

To date, however, while there has been a comprehensive series of studies of the molecular and ultrastructural basis of regeneration in many species of echinoderms, there have been no cell lineage tracking studies. Only cell tracking can definitively establish the origin and trajectory of cells during regeneration and resolve the debate as to the role of stem cells versus cellular reprogramming in echinoderms. Cell tracking however is technically challenging, especially in adult echinoderms where there are many cells and cell types, and regeneration proceeds over days or weeks. Transgenic tools are also limited in adult echinoderms. Indeed, the challenges associated with accurately tracking cell lineages have greatly limited the taxonomic distribution of animals for which we have this knowledge across the metazoa.

Here we sought to fill this important gap by turning to the echinoderm larval regeneration model. Echinoderms, typically for many marine invertebrates, have a biphasic lifestyle, producing a planktonic larval form that exists for up to many months before undergoing dramatic metamorphosis. It has now been well documented that the larval forms are also capable of extensive regeneration (Vickery et al., 2001; Kasahara et al., 2019 ). We have recently introduced the larval sea star Patiria miniata as a model system for the study of whole body regeneration (Cary et al., 2019b). Sea stars, as typical for echinoderms, have extensive regenerative capacities, a feature which extends across both their adult and larval life phases (Vickery et al., 2001, 2002; Ben Khadra et al., 2017; Vickery et al., 2002; Ben Khadra et al., 2018; Hernroth et al., 2010; Oulhen et al., 2016). Although pentaradial as adults, there are many parallels between echinoderm larval development and early vertebrate development, particularly in the formation of the anterior-posterior axis and development of the nervous system (Angerer et al., 2011; Hinman and Burke, 2018; Range et al., 2013). Therefore, while vertebrates and sea stars have very different regenerative capacities, there are commonalities in their early development. There are also extensive genomic resources (Cary and Hinman, 2017; Cary et al., 2019a, 2018, 2017; Gildor et al., 2019) and detailed developmental GRNs available for $P$. 
miniata (Cary et al., 2020) allows comparisons between developmental and regenerative GRNs and clear gene orthology mapping.

Previous work has shown that when these sea star larvae are decapitated, they are able to regenerate their anterior structures (Cary et al., 2019b; Oulhen et al., 2016; Vickery et al., 2001). Larvae have an anterior serotonergic nervous system, which we show here is removed by this decapitation. Extensive previous work in P. miniata embryos has shown how these neurons form during embryogenesis. The SRY-box transcription factor (TF), sox2 (formerly soxb1), is expressed broadly throughout the ectoderm by blastula stage (Yankura et al., 2010). Sox4+ (formerly soxc) neural progenitors arise in the ectoderm, and then divide asymmetrically to produce LIM homeodomain TF Ihx2+ (formerly Ihx2/9) daughter cells, which in turn divide asymmetrically to form differentiated serotonergic neurons (Cheatle Jarvela et al., 2016). This occurs within the anterior ectoderm, which expresses TFs such as six 3 and foxq2, and is a wnt ligand negative territory (Cheatle Jarvela et al., 2016; Yankura et al., 2013, 2010).

In this study we took advantage of cell type specific markers of differentiated neurons to confirm that the sea star larvae are able to regenerate their anterior nervous system. We establish a novel cell lineage tracking system to determine the cellular origin of these regenerated neurons. This allows us to specifically test whether regenerated neurons arise through embryonic neurogenesis pathways, and to determine the origin and potency of progenitors. Using a small molecule inhibitor of nuclear DNA replication, to question whether new gene expression can arise in the absence of divisions that are a prerequisite of stem cell origin, we show that expression of the putative pluripotency factor, sox 2 is induced in previously sox 2 minus cells at the wound site. As this occurs even in the absence of new cell division, this result suggests that these cells are respecified rather than arising from asymmetric stem cell division. Both the newly induced and existing, sox2+ cells now give rise to new sox4+ neural precursors that then proceed along an embryonic neurogenesis pathway to reform the anterior nervous systems. The sox2+ cells contribute to only neural and ectoderm lineages, indicating that these progenitors maintain their normal, embryonic lineage restriction. 


\section{Results}

\section{Patiria miniata larvae fully regenerate their nervous system}

Sea star bipinnaria larvae have an extensive nervous system (Katow et al., 2009; Murabe et al., 2008; Nakajima et al., 2004); (Carter et al., 2021; Elia et al., 2009; Hinman and Burke, 2018). Figure 1A-B" shows the seven day post fertilization (7dpf) P. miniata larval nervous system labeled via localization of anti-synaptotagmin B (SynB) and serotonin antibodies. It has been shown that the pan-neuronal marker SynB labels all neurons in many echinoderm species (Burke et al., 2006; Nakajima et al., 2004). The neural bodies and axonal tracts are apparent throughout the two ciliary bands, the lip of the mouth, domains lateral to the mouth that mark the location of the apical ganglia in this stage, and the esophagus (Fig 1A). Serotonin immunoreactivity is concentrated predominantly in the anterior part of the larvae; in the dorsal ganglia with a subset of cells across the aboral surface (Fig 1B, 1D', 1E'). The presence of serotonin, characteristic neural cell morphology including long axonal processes and lack of markers of cell division, are taken as evidence that these are differentiated cells.

We have shown previously that larvae are able to regenerate their anterior body when they are bisected below the mouth (Cary et al., 2019b) (Fig 1D-I, SP 1). This bisection, therefore, removes much of the anterior nervous system, including the anterior ciliary band loop (preoral ciliary band), the dorsal ganglia, as well as the mouth and its associated neurons. We tested whether these bisected larvae regenerate their nervous system. By one week post bisection (Fig 1 C-C'), we find neural bodies and axonal tracts along the newly formed anterior ciliary band and complex neural networks lateral to the mouth suggestive of the dorsal ganglia. The reformed mouth also has associated neurons. We also specifically examined the serotonergic neurons (Fig 1D'-i). This neural subtype is found in the dorsal ganglia where they are present as clusters of large cell bodies with long axonal processes (Fig 1D'-e). These cells originally form in the anterior-most ectoderm of the late gastrula but migrate posteriorly to a location dorsal to the mouth in the larva (Cheatle Jarvela et al., 2016; Yankura et al., 2013). Serotonergic neurons are also found on the lower lip of the mouth where they have smaller cell bodies and shorter axonal processes. We therefore reasoned that serotonergic neural bodies were removed entirely by our manual bisection protocol. Indeed, when we bisect the larvae across the midline, 40 of 45 stained larvae show no remaining serotonergic neurons one day later, when they were 
first assayed. Fig 1F'-f shows one such example. Of the remaining five, only one or two cells were found which, due to their location, are likely those normally associated with the lower lip of the mouth.

By examining a time series of regeneration we show that serotonergic neurons are first revealed by antibody staining at the anterior regenerating leading edge in 8/14 larvae five days following bisection (Fig 1 G'-g). By 7 days post bisection (dpb), serotonergic neurons are found in 12/15 regenerating larvae at the anterior edge (Fig $\left.1 \mathrm{H}^{\prime}-\mathrm{h}\right)$. Three weeks following bisection, the regenerated serotonergic neurons are bilaterally patterned at the dorsal side of the regenerating larvae, resembling the dorsal ganglia structure found in intact larvae (Fig 1l'-i).

These data therefore show that the anterior serotonergic neurons are removed following anterior bisection and are reformed in the correct general location and with extensive axonal projections by 21 days of regeneration.

\section{Embryonic neurogenesis pathways re-emerge during regeneration}

We next questioned whether the regenerated serotonergic neurons formed using the embryonic neurogenesis pathway. We have shown that, during normal embryogenesis, the SRY-box TF, sox2, (formerly soxb1) is expressed broadly throughout the neurogenic ectoderm (Yankura et al., 2013). Serotonergic neurons form from cells expressing the SRY-box TF, sox4 (formerly soxc) that are first present and distributed in a "salt and pepper" pattern throughout the ectoderm of the embryonic blastula (Yankura et al., 2013, 2010). Two transcription factors, foxq 2 and six 3 are expressed in the anterior ectoderm of the early gastrula and are required for the correct progression of the anteriorly most located sox4+ neural progenitors to become $/ h \times 2+$ cells. After asymmetric cell divisions, $I h \times 2+$ progenitors in turn give rise to post-mitotic neurons expressing elav (Fig 2A-C). These post-mitotic neurons will produce serotonin when they mature (Cheatle Jarvela et al., 2016). Thus we sought to determine whether these genes are re-expressed following bisection. If so, this can provide the first indication that embryonic neurogenesis is reactivated during regeneration.

Following bisection, we find that foxq 2 and six 3 are expressed in the anterior ectoderm of the leading regenerating edge by $3 \mathrm{dpb}(\mathrm{Fig} 2 \mathrm{D}, \mathrm{SP} 2 \mathrm{~A}-\mathrm{H})$. It is important to note therefore, that foxq2 is now expressed in cells that, in the normal larvae, reside along the middle of the AP axis and would never normally express anterior markers such as foxq2. We find similar patterns with 
other regulatory genes that are expressed along the embryonic AP axis, with wnt3 re-expressed in posterior regenerating larvae (SP 2I-K). This indicates that the anterior leading edge cells are being respecified, as defined by expressing new sets of genes, during regeneration. This respecification, at least partially, recapitulates the embryonic axial state required for neurogenesis.

Sox2 is expressed at low levels throughout the ectoderm of the normal larvae (Yankura et al., 2013) (SP 3A) but within one day following bisection, sox2 expression is dramatically up-regulated at the wound site (Fig 2E-e, SP 3B), when compared to larval expression levels. We have previously shown that cell division occurs throughout the normal larva, but then decreases in the early bisected larva and is then predominantly localized to the wound adjacent anterior at 3dpb (Cary et al., 2019b). Thus localized sox2 expression precedes the formation of the proliferative zone but then remains within this anterior region. This regenerative proliferative zone is readily visualized by staining for 5-Ethynyl-2'-deoxyuridine (EdU), by incubating larvae for one to six hours in EdU sea water. This costaining shows that sox 2 is highly expressed throughout this ectodermal zone and within some of these proliferating cells at $3 \mathrm{dpb}$ (Fig 2F-f, SP $3 \mathrm{C}$ ) and that this remains through to $5 \mathrm{dpb}$ (Fig 2G-g, SP 3D).

Sox4 expression, a marker of neural precursor cells, is also observed at the wound site within one day following bisection (Fig 2H-h', SP 3F). In 3dpb larvae, sox4 expression is detected at the regeneration leading edge (SP $3 G$ ). Fluorescent labels allow for the detection of coexpression of genes and colocalization of gene expression with EdU staining. The large number of cells at these stages make colocalization difficult to establish through conventional confocal microscopy and thus we used Imaris Software (Oxford Instruments) 3D visualization analysis to identify overlapping signals with confidence (Imaris visualization is shown Fig 2 h', i' j', k1, k2). Thus we show that sox4+ cells clearly undergo cell divisions as FISH staining colocalizes with EdU (Fig 2l-i'). Proliferating sox4+ cells are also detected in the regenerating ectodermal/endodermal mouth (Fig 2l). By $5 \mathrm{dpb}$, sox4 expression is concentrated to the regenerating anterior, again in dividing cells (Fig 2J-j', SP $3 \mathrm{H}$ ).

The expression of $I h \times 2$ is also detected by $5-7 \mathrm{dpb}$ in dispersed cells at the regenerating leading edge (Fig 2K-k2, SP 3J). Similarly, the expression of post-mitotic neural marker elav is also restored at the regenerating anterior at 5-7dpb (Fig 2L-l', SP 3L). Two color FISH shows that, 
similar to embryogenesis, sox4/lhx2 co-expression is found in cells located at the lateral sides of the regeneration leading edge (Fig $\left.2 \mathrm{~K}-\mathrm{I}^{\prime}\right)$ and that $l h \times 2$ and elav are also co-expressed.

Collectively, these data show that bisection leads to the activation of embryonic neurogenesis gene expression states. Sox 2 and sox4 expressions are induced upon wounding, and sox4+ cells located at the lateral leading edge give rise to $l h \times 2+$ cells. The $I h \times 2+$ cells at the leading edge in turn become post-mitotic neurons expressing elav (Fig 2M). The location of $/ h x 2$ expression at the leading edge, within the zone of foxq2 expression, also recapitulates the spatial localization of embryonic serotonergic cell specification.

\section{Newly specified sox4+ neural cell lineage is induced by bisection}

The gene expression states propose the intriguing model that neural progenitors, i.e. newly specified sox4+ cells, arise at the leading edge following bisection, and that these newly specified neural progenitors will reform the serotonergic neurons by entering the embryonic neurogenesis pathways. To test this hypothesis, we needed to establish a lineage tracing system that would distinguish new sox4+ cells from existing sox4+ cells and also follow their fate for several days.

To this end, we developed a highly stable, photoconvertible expression reporter. We modified an approach we have used previously in which EGFP (GFP) was homologously recombined into the sox 4 coding region of a Bacterial Artificial Chromosome (BAC) clone, to replace the coding sequence of sox4 with that of GFP while leaving the endogenous basal promoter and 5'UTR in place (Buckley and Ettensohn, 2019). When the sox4:GFP recombinant BAC is injected into embryos, it faithfully expresses GFP in sox4+ cells, recapitulating endogenous sox4 expression (Cheatle Jarvela et al., 2016). It should be noted that transgenic DNAs are inherited mosaically and thus any individual larva expresses the reporter in only a subset of cells. This demonstrates that the approximately $150 \mathrm{Kbp}$ surrounding the genomic locus of the sox4 coding region, including the endogenous basal promoter, is sufficient to drive correct expression of the transgenic GFP reporter gene.

We now exchanged GFP for the photoconvertible Kaede sequence. Kaede fluorescent protein (Kaede FP; (FPbase ID: Q31FH)) stably converts from green to red after exposure to UV light (Ando et al., 2002). We experimentally measured the stability of Kaede, by injecting in vitro synthesized kaede mRNA into zygotes and quantifying fluorescence over time. We show that 
translated Kaede protein is detectable above background for at least 7 days in $P$. miniata embryos and larvae when grown at $15 \mathrm{deg}$ C (SP 4, SP File1). This supports previous work which shows that GFP is extremely stable in these embryos, likely because they are grown at low temperatures (Arnone et al., 1997).

The sox4:Kaede BAC construct (Fig 3A) was injected into zygotes, and larvae were grown to 7dpf bipinnaria larval stage. They were then bisected and immediately photo-converted by exposure to $405 \mathrm{~nm}$ light (SP 4, SP File1). Larvae were inspected under fluorescent microscopy to assess photoconversion, and we confirm that all cells that had expressed sox4 within the previous 7 days now fluoresce at $560 \mathrm{~nm}$ (red). Decapitated larvae were then individually cultured in 24-well dishes so that we could follow individual cell populations in each larva (Fig 3C). At 2dpb and 3dpb we observe green-only, red-only, as well as yellow (green plus red) cells (Fig 3B, D-d3). Red cells in the regenerating larvae are the historically labeled cells that have expressed sox 4 at some point prior to bisection but no longer express sox4. For example, these may have been differentiated neurons that no longer express the progenitor marker sox4. The yellow cells are from existing larval and regenerative sox4+ cell lineages. That is, these cells expressed sox 4 in the intact larvae and continue to express sox 4 in their progeny after wounding. Most interestingly, there are green-only cells. These are cells that have not previously expressed sox4 but are induced to start expressing sox 4 only upon decapitation.

We questioned whether the presence of newly expressing sox4+ cells is induced by wounding, or whether there is normally a pool of progenitor cells that are set to become sox4+ over the timepoints we observed. We therefore compared the rate of sox4+ cell specification between embryogenesis and larval development. We again injected Sox4:Kaede BAC into zygotes and photoconverted either $2 \mathrm{dpf}$ embryos or $4 \mathrm{dpf}$ larvae (Fig 4A). We then quantified the numbers of green, red and yellow cells 3 days later ( $5 \mathrm{dpf}$ or $7 \mathrm{dpf}$ ) over normal development (i.e. without bisection, SP File1). We find that there are high numbers of green+ cells in larvae photoconverted at 2dpf (Fig. 4B-C), but almost none in larvae converted at 4dpf (Fig 4D-E).

This is evidence that new sox4+ cells are actively being specified in embryos, but that this specification has stopped by 4dpf (i.e. larval stage). Comparing the numbers of green (newly expressing) sox4+ cells during normal development with those counted in regeneration, we see that specification of new sox4+ cells is highest in embryos, ends by late embryogenesis, and resumes in response to bisection induced regeneration (Fig 4F, SP File1). Thus decapitation 
induces a wound response that re-initiates the specification of new sox4+ cells, a process which had stopped by day four of embryogenesis. These sox4+ cells then reenter into embryonic neurogenesis pathways (Fig 2).

\section{Sox2+ progenitor cells are specified to Sox4+ cells to regenerate neurons}

We have shown that there arises a new population of sox4+ cells induced by bisection. During normal embryogenesis, the neural precursor cells are derived from sox $2+$ ectoderm. Sox 2 is expressed throughout the ectoderm in embryos and therefore broadly marks this germ layer (Yankura et al., 2013, 2010). We therefore asked whether these new bisection induced neural progenitors similarly arise from ectodermal lineages.

Our gene expression analysis showed that sox 2 is broadly upregulated throughout the anterior of the regenerating larva (Fig 2E-g) and that new, dividing, sox4+ cells also form in this region (Fig 2H-j, 3D). We therefore generated a sox2:Kaede BAC. We first tested whether this BAC recombinant recapitulated normal Sox2 expression in sea stars. After BAC injection, zygotes started to express Kaede at 24-48hpf in broad patches of ectodermal cells. By larval stage, Kaede was detected on the ectoderm including the ciliary bands, dorsal ganglia and ectodermally derived neurons (SP 5A-C'). This localization pattern recapitulates the embryonic sox2 expression pattern reported previously (Yankura et al., 2013, 2010); SP 3A).

We next generated a sox4:Cardinal BAC recombinant so that we could examine the potential colocalization of sox2+ and sox4+ lineages. This is the same BAC recombinant as sox4:Kaede (Fig 3A) but with the Kaede coding sequencing replaced by Cardinal (FPbase ID: 7EWEM), which fluoresces in the far-red range $(633 \mathrm{~nm})$. These two BAC recombinants were co-injected to identify potential double labeling of sox2+ cell lineages (green, red or yellow depending on the assay) and sox4+ cell lineages . It is important to note that multiple constructs when co-injected into echinoderm zygotes are then co-integrated, and are therefore inherited in the same cellular lineages (Cheatle Jarvela et al., 2014). When we examine expression in normal developing larvae, we find that sox4+ lineages overlap completely with sox2+ lineages on the ectoderm as is expected in normally developing larvae (SP 5D-D"), although not all sox2+ cells are sox4+ as sox2+ also produce non neural ectoderm.

We next photo-converted the double BAC recombinant larvae (i.e. all sox2:Kaede ${ }^{+}$lineage cells are converted to red), and immediately bisected the larvae and allowed them to regenerate for 2 
to 3 days (Fig 5A). Strikingly, we found new (green+ cells) expression of sox2, indicating that cell lineages that had not previously expressed sox2 are now expressing the sox 2 gene following bisection. Furthermore, four of 15 observed larvae exhibited cells with colocalized green Kaede (new sox2 expression) and Cardinal (sox4,far red, pseudo-colored blue) at the regenerating leading edge (Fig 5B-b3) at 3dpb. For example, in the larva shown in Fig 5B, there are 3 cells located at the left side of the regeneration leading edge that contain green Kaede and Cardinal. As the green Kaede reporter labels de novo sox2 expression, this shows that these new sox $2+$ cells start to express sox 4 and thereby enter into neurogenesis pathways. Our whole mount in situ analyses in Fig 2 also suggested that there will be significant new sox2+ cells, and that these will become sox4+. The Cardinal reporter can potentially represent both pre-existing and regenerative sox4 expressions. However, it is important to note that at the time of bisection, all labeled sox4+ cells overlapped with sox2+ lineage in the imaged larvae. In other words, all Cardinal+ cells are also red Kaede+ at the time of photoconversion. Thus the sox4:Cardinal in 5B must be expressed after wounding. This therefore supports the hypothesis that cells derived from non sox $2+$ lineages are induced to express sox 2 in regenerating larvae and will contribute to neural progenitors. Indeed when we follow these larvae through to $7 \mathrm{dpb}$ (SP 6A-B) we find fluorescence in the neural projections which are characteristic of fully formed neurons (SP 6a1-a3).

\section{Bisection induced Sox2+ cells maintain usual embryonic lineage restriction.}

We were interested to determine whether these newly specified sox $2+$ cells, which were not previously ectodermal, now maintain an ectodermal lineage. We examined at least 10 larvae over three independent injection batches and found that in all regenerating larvae the newly expressing sox2+ cells contributed to only tissues normally derived from sox2+ lineages (e.g. SP 5E-F"). We observed sox2:Kaede green cells in the outer ectodermal epithelium, the mouth, and ciliary bands. This indicates that once induced this lineage will maintain its normal, embryonic lineage potential.

It is worth noting that not all sox2+ cells enter the neurogenesis pathway in regeneration (Fig $5 \mathrm{C}$-c3). For example, in the larva shown in Fig 5C, there are 2 cells at the regeneration leading edge that contain both green and red Kaede, derived from the sox2 lineage. These cells do not 
express sox4:Cardinal by $3 \mathrm{dpb}$. This suggests that while larval sox2 cell lineages are restricted to ectodermal potency, they do not necessarily contribute only sox4+ neural fates.

\section{New sox2 expression is induced in the absence of cell division}

Finally, we questioned whether new sox 2 expression could arise in the absence of cell division. Stem cells, by definition, require an asymmetric division to produce a new daughter cell type and maintained stem cell. Thus new sox 2 expression should not be present when cell division is blocked if it is solely derived from asymmetric stem cell division. We bathed sea star larvae in Aphidicolin, a conserved inhibitor of cell division, that is particularly well characterized in echinoderms where it is known to block DNA polymerase function, nuclear break down and microtubule organizing centers (Mashanov et al., 2017; Nishioka et al., 1984). We first used a serial dilution test to determine that the 25 microM of Aphidicolin was the minimum concentration needed to reliably inhibit cell division as assayed by EdU staining, while cells in DMSO controls divided normally (Fig 6B). We then microinjected the sox2:Kaede recombinant into fertilized oocytes, bisected 7dpf larvae, photoconverted and added Aphidicolin or DMSO as a control in the sea water immediately after post bisection. Bisected transgenic larvae were incubated in inhibitor/control solutions over three days (Fig 6A). We then assayed for red, green or yellow positive cells (Fig 6C-D"). We show that there are multiple yellow, green cells along the leading regenerated edge. This confirms that cells which were not previously expressing sox2 are now able to initiate expression of this gene in the absence of cell division and are thus not the result of asymmetric stem cell division.

This experiment additionally addresses a concern that green FP only cells may actually be Green+Red, but have lost red FP signal through dilution if the precursor cells are highly proliferative. We thought this unlikely as green+ FP cells are identified prior to extensive regenerative proliferation and we individually followed larvae to track previously identified Red FP cells. We now however, can definitely exclude dilution based on proliferation as a cause for loss of Red FP as Green FP cells emerge in the absence of any division. 


\section{Discussion}

The ability that some animals have to restore tissues and body parts following traumatic injury challenges our current understanding of the mechanisms of cell specification and differentiation. Significant questions remain surrounding the source of new cells needed to regenerate lost tissues and organs, their potencies and whether developmental GRNs are re-used. A further open question is whether any of these processes are shared across taxa, and can explain the differing capacities for regeneration.

Echinoderms are an especially important system for the study of these questions as they are well known for their extensive capacities for regeneration (Ben Khadra et al., 2018; Byrne, 2020). There has, therefore, been extensive research on regeneration of multiple species, tissues and stages in echinoderms (Vickery et al., 2001; Kasahara et al., 2019; García-Arrarás et al., 2019; Mashanov and Zueva, 2019; Piovani et al., 2021; Zhang et al., 2017; Di Benedetto et al., 2014). While providing important insight and an emerging consensus on the role of local dedifferentiation, the availability of transgenic tools has precluded the cell lineage analysis needed to definitively identify cell sources and their potencies. The discovery that many echinoderm larvae are able to regenerate (reviewed in Wolff and Hinman, 2021), opens the possibility to use genetic engineering tools that are available for embryos, to probe regeneration. Additionally, developmental GRNs and the cell specification pathways are extremely well characterized for many species of echinoderms, providing an opportunity to compare developmental to regenerative GRNs of the same larval cell types. In this study, we develop a new BAC-based transgenesis protocol to identify and track the cellular sources of regenerated neurons of the sea star bipinnaria larva, and to compare neurogenesis pathways between development and regeneration. To our knowledge, this is the first time that any cell lineage tracing studies have been performed in echinoderm regeneration.

We show that bipinnaria larvae of the bat star, P. miniata, are able to regenerate their anterior nervous system. Sea star larvae have remarkably complex nervous systems (Carter et al., 2021; Elia et al., 2009) given their small size and presumably simple behavior. We took 
advantage of the highly specific marker of differentiated serotonergic neurons, which includes immunoreactivity to anti-serotonin antibody (Sigma, S5545), characteristic axonal projections, and location within the larvae, to confirm that these neurons are removed by surgery and reform within 21 days. The removed pre-oral ciliary band and lip of the mouth are also reformed during regeneration.

We used fluorescent in situ hybridization (FISH) to show that genes involved in embryonic AP axis specification are re- expressed along the axis of bisected larvae. For example, foxq2, six 3 and wnt3 are key nodes in the embryonic GRN for axial specification (Cheatle Jarvela et al., 2016; Yankura et al., 2013), and are re-expressed along the AP axis of the posterior regenerating segment. Reestablishing axial patterning is a commonly observed early feature in many species undergoing whole body regeneration (Gehrke et al., 2019; Reddien, 2019), which we now show also occurs in sea star larvae. Sox2 and sox4 expression is similarly induced adjacent to the wound site within one day. This region will form a proliferative epithelial zone by the third day following bisection. In embryos, sox 2 is expressed throughout the ectoderm, while sox4+ cells are scattered throughout the ectoderm where they function as precursors for multiple neural types in the larvae (Cheatle Jarvela et al., 2016). This is the first indication that there is a resetting of gene expression states adjacent to the wound and is consistent with a broad respecification of these cells.

One of the most fascinating questions in regeneration is whether animals reuse their embryonic GRNs to regenerate cell types. If different pathways are used, this indicates that there are regeneration specific GRNs deployed after traumatic wounding. This further suggests that such pathways may independently evolve under different selection pathways than the embryonic pathways. If embryonic GRNS are reused, the challenge is to understand how they are reactivated in non-zygotic cells. The new expression of embryonic axial patterning genes across the bisected larva (Fig. 2C-D) is consistent with re-entry into an embryonic state. We further show, using FISH and using IMARIS to confidently assess colocalization of signal, that sox2+ cells overlap with sox4+ cells, that sox4 expression overlaps with $/ h x 2$ expression, which in turn overlaps with elav (Fig 2). We have previously demonstrated that these gene products mark the embryonic neurogenesis pathways, and that ectodermal elav expression is a marker of differentiated neurons (Cheatle Jarvela et al., 2016). We have also previously shown that $l h x 2$ is needed for the differentiation of serotonergic neurons (Cheatle Jarvela et al., 2016). This data therefore supports the hypothesis that embryonic serotonergic neurogenesis pathways are 
reactivated in the induced sox2+ cells, although we are not yet able to show that any of these gene products are functionally required for neurogenesis in the regeneration context.

The presence of sox2+ and sox4+ cells adjacent to the wound site provide the possibility that these are the cellular source of regenerated neurons. Cell lineage tracing however is needed to test whether these cells do indeed form neurons, and to identify the cellular origin of sox 2 and sox4 expression. The wound adjacent expression could arise from existing sox $2+$ or sox4+ cells in the larvae. This would suggest that these cells function as a resident stem cell population of regenerated neurons. Alternatively they would arise from other, existing, cells, which may either be derived from an additional source of stem cell or through de- or trans-differentiation. We therefore developed a novel transgenic cell lineage reporter system based on BAC recombineering that takes advantage of highly stable, irreversibly photoconvertible, fluorescence Kaede reporter (Ando et al., 2002). In the system we developed, cells that are currently expressing the gene of interest will fluoresce green, and may also contain red FP if they have previously expressed the gene prior to photoconversion. Using this reporter system, we show that the sox4 gene is expressed in existing sox4+ cells, and in cells that have not expressed sox4 within the last seven days (Fig 3). We reasoned that new neural precursor cells (i.e. green only sox4+ cells) may be continuously generated as a normal development process and therefore not specifically induced by wounding. We therefore compared the formation of new sox4+ neural precursors in development and regeneration. We find many new sox4+ cells being produced in early embryos (day 2 to 5 development) as expected, but this has almost entirely stopped by swimming larval phase (day 4 to 7 development) and resumed upon wounding (Fig 4). The subsidence of sox4+ cell formation in the larval stage is consistent with data showing that the serotonergic postmitotic neuronal number is stable in larvae from day 4 or 5 of development (SP 7). Using the same experimental strategy, but now with sox2 BAC reporter, we show the sox2 gene is also expressed in existing and new cells. Using an additional Cardinal reporter, we show that some, but not all, of these new sox2+ cells become sox4+ (Fig 5), indicating that they can become neural precursors but also other cell types. We followed these reporters through regeneration to show that they are later found in cells with characteristic axonal projections and located in the lower lip of the mouth, and dorso-lateral domains adjacent to the mouth as stereotypic of serotonergic neurons. Thus we show that these wound-induced sox 2 cells do become neurons, other ectodermal cells and mouth endo/ectoderm in a similar lineage potential as the embryonic sox $2+$ lineage. 
The existing, sox2+ sox4+ cells that continue to express these genes (i.e. the yellow cells in our assay) likely function as resident ectodermal- and neural- stem cells as we show that they are dividing and contribute to neural and ectodermal tissues. We wanted to investigate whether the new sox $2+$ cells (green) arose from existing cells or might arise from another, possibly totipotent resident stem cell population. As stem cells must, by definition, divide to produce a daughter that can be directed along a new differentiation pathway we used small molecule inhibitors to block cell division following bisection. We find that new sox2+ cells still emerge in these larvae (Fig. 6). This therefore shows that new sox2+ expression does not require the asymmetric division from a stem cell progenitor, and instead, therefore, is the result of respecifying existing cells.

The human and mouse orthologs of the sea star sox2 gene have well characterized functions in the induction of pluripotency and maintenance of stem cells, especially neurogenic stem cells (Feng and Wen, 2015). In combination with Oct4, KIf4 and c-Myc, sox2 can reprogram human and mouse somatic cells to pluripotent states (Soufi et al., 2015; Takahashi and Yamanaka, 2006). Other models of echinoderm regeneration have implicated, although not demonstrated, a role for orthologs of these pluripotency factors in de-differentiation (Mashanov and Zueva. 2019; Mashanov et al., 2015a). We have also previously shown that Klf4 is expressed at the wound edge following bisection and is thus presumably co-localized with sox2 (Cary et al, $2019 b)$. The new wound-induced expression of sox2, therefore presents the hypothesis that induction of sox 2 expression is the actual cause of the dedifferentiation of cells, and/or may now function to maintain an ectodermal stem cell population. We have not yet formally shown whether new induction of sox2 leads to dedifferentiation (i.e. reprogramming into a progenitor state), or whether there are other types of reprogramming, as we do not know the differentiation state of cells induced to express sox 2 or whether these cells now adopt an identical molecular signature to existing sox 2 cells. The extent of lineage conversion are unknown and open questions in stem cell biology in any system, and yet is critical knowledge for translational applications of stem cells. The work here provides foundational knowledge in a tractable system to work towards answers to these questions. We have shown that once respecified, sox2+ cells are restricted to become ectoderm, and the lip of mouth ectoderm/endoderm cell types, indicating that they are multi-potent but germ-line restricted. In embryos, sox2+ cells are also restricted to ectodermal lineages and the lip of the mouth, and therefore, the wound-induced sox2+ cells now enter their normal, embryonic lineage. A subset of these 
induced cells recapitulate an embryonic neurogenesis pathway to reform serotonergic neurons around the mouth, and the latero-dorsal ganglia.

As new model systems are added to the study of regeneration, they present an opportunity to re-examine our understanding of regeneration and the ways in which cellular reprogramming is induced by wounding. Early concepts around cellular origins of whole body regeneration suggested a dichotomy between use of stem cells and de- or trans-differentiation. For example, the freshwater planarian, Schmidtea mediterranea, utilizes a population of heterogeneous, pluripotent somatic stem cells, called neoblasts, to proliferate and differentiate to replace body parts (Sánchez Alvarado, 2006). Conversely species such as Hydra and axolotl, refate differentiated cells either through dedifferentiation or transdifferentiation (Gerber et al., 2018). Cellular plasticity also varies widely, from the totipotent planarian neoblasts to lineage restricted progenitors used by vertebrate animals (Kragl et al., 2009) (Zhu and Pearson, 2016). Our data indicate that echinoderm larvae induce non-stem cells into ectodermal neural stem cells, possibly through dedifferentiation or other mechanisms of fate conversion as we see de novo sox2+ cells becoming neurons in regenerating larvae. This is reminiscent of the mechanisms of cnidarian models such as Hydra. Additionally, we show that there is a maintained lineage of sox2+ and sox4+ progenitors in bisected larvae, also reforming the nervous system, as we see yellow neurons in regenerating larvae (SP 6A). Interestingly, this at a broad level echoes the use of lineage restricted stem cells seen in vertebrates. We posit that echinoderms may have a natural capacity to maintain a cellular plasticity that permits induction of new lineage stem-cells, as well as an ability to use existing lineage-restricted stem cells and that this flexibility may underlie their extensive abilities for regeneration.

\section{Materials and Methods}

\section{Culture and regeneration}

Adult Sea star, Patiria miniata, were obtained from the southern coast of California, USA (Pete Halmay or Marinus Scientific) and housed in artificial sea water (ASW, Instant Ocean, Aquarium Systems) at $12-15^{\circ} \mathrm{C}$. Embryos were cultured in ASW and fed Rhodomonas lens ad libitum as previously described (Cheatle Jarvela and Hinman, 2014). All studies of regenerating larvae were conducted with larval cultures beginning at $7 \mathrm{dpf}$ at which point the larvae were manually bisected stereotypically through the foregut, midway along the AP body axis as described earlier 
(Cary et al., 2019b). Regenerating larvae were photographed using differential interference contrast (DIC) optics over the course of regeneration on a Leica DMI4000B microscope at 100x magnification using Leica Application Suite software (Leica; Wetzlar, Germany).

Whole mount in situ hybridization (WMISH)

Embryos, intact and regenerating larvae for WMISH were fixed in 4\% paraformaldehyde (PFA) in a high salt MOPS-fix buffer (100 mM MOPS pH 7.5, 2 mM MgSO, 1 mM EGTA, and $0.8 \mathrm{M}$ $\mathrm{NaCl}$ ) for 90 minutes at room temperature or overnight at $4^{\circ} \mathrm{C}$. Following fixation, embryos were washed in (v/v) 25\%,50\%, 75\% and 100\% ice-cold 70\% ethanol. Fixed embryos and larvae were stored at $-20^{\circ} \mathrm{C}$. WMISH was conducted as described previously (Hinman et al., 2003; Yankura et al., 2010) with the following modification. Hybridization of sox4 and Ihx2 riboprobes (final concentration of $0.2 \mathrm{ng} / \mathrm{mL}$ ) was performed at $55^{\circ} \mathrm{C}$ for 5 days. Hybridization of elav riboprobes (final concentration of $0.2 \mathrm{ng} / \mathrm{mL}$ ) was performed at $58^{\circ} \mathrm{C}$ for 5 days. Hybridization of foxq2, wnt3 and six3 riboprobes (final concentration of $0.1 \mathrm{ng} / \mathrm{mL}$ ) was performed at $58^{\circ} \mathrm{C}$ for 5 days. Larvae were imaged on a Leica DMI4000B inverted light microscope using DIC microscopy at 100x magnification and the Leica Application Suite software (Leica; Wetzlar, Germany).

Double fluorescent in situ hybridization (FISH)

Intact and regenerating larvae of P. miniata at the indicated time points were fixed in a solution of $4 \%$ paraformaldehyde in MOPS-fix buffer (0.1 M MOPS pH 7.5, $2 \mathrm{mM} \mathrm{MgSO}_{4}, 1 \mathrm{mM}$ EGTA, and $0.8 \mathrm{M} \mathrm{NaCl}$ ) for 90 min at room temperature and transferred into $70 \%$ ethanol for long term storage at $-20^{\circ} \mathrm{C}$. Double FISH experiments were performed as previously described (McCauley et al., 2013) using digoxigenin-labeled antisense RNA probes (final concentration of 0.1-0.2 ng/mL) and dinitrophenol-labeled antisense RNA probes (final concentration of 0.1-0.2 $\mathrm{ng} / \mathrm{mL}$ ). Hybridized probes were detected using anti-DIG-POD antibody (1:1000, Roche), anti-DNP-HRP antibody (1:1000, Perkin Elmer) and tyramide signal amplification (Perkin Elmer). A 1:100 dilution of Cy3 or FITC labeled tyramide in an amplification buffer was used to treat larvae for $7 \mathrm{~min}$ at room temperature in the dark. A Cy3- or FITC-labeled tyramide was deposited near the hybridized probe in a horseradish peroxidase mediated reaction. This allowed for fluorescence detection of labeled probes. During PBST washes, larvae were incubated for a total of $20 \mathrm{~min}$ in solution with 1:10000 dilution of $10.9 \mathrm{mM} \mathrm{DAPI}$, followed by 
PBST washes. Larvae were photographed with Zeiss 880 Laser Scanning Microscope at 200x magnification with $405 \mathrm{~nm}, 488 \mathrm{~nm}$ and $560 \mathrm{~nm}$ channels in Z-stack settings.

\section{EdU-FISH}

Labeling and detection of proliferating cells in $P$. miniata intact and regenerating larvae were performed using the Click-it Plus EdU 488 Imaging Kit (Life Technologies), with the following modifications. Larvae were incubated in a $10 \mu \mathrm{M}$ solution of EdU for $15 \mathrm{~min}$ or $6 \mathrm{~h}$ in seawater at $15^{\circ} \mathrm{C}$ followed by immediate fixation in $4 \%$ PFA in PBS buffer with $0.1 \%$ Triton $\mathrm{x}-100$. Fixation was performed at room temperature for $90 \mathrm{~min}$. FISH was conducted as described above in the double FISH method with the following modification. Either FITC- or Cy3-labeled tyramide was used to detect labeled probes.

Immuno-fluorescent (IF) staining

Whole mount IF staining was performed as described elsewhere (Cheatle Jarvela et al. 2016). Briefly animals were fixed in 4\% PFA prepared in PBS $(\mathrm{pH} 7.4)$ at room temperature for 15 minutes. The samples were post-fixed in ice-cold methanol for $10 \mathrm{~min}$, allowing for setting of larvae by gravity. The samples were then washed in PBS, permeabilized in PBS/0.5\% Triton $\mathrm{X}-100$ for $30 \mathrm{~min}$, then incubated in $0.1 \mathrm{M}$ glycine for $30 \mathrm{~min}$ to quench autofluorescence. After another wash in PBS/0.1\% Triton X-100 (3 ×15 min), the larvae were blocked using 3\% BSA/PBS $/ 0.1 \%$ Triton $\mathrm{X}-100$ for $1 \mathrm{~h}$. The primary antibodies (SP Table 1 ) were applied at $4{ }^{\circ} \mathrm{C}$ overnight. After extensive washing in PBS/0.1\% Triton X-100 (6×15 min), the samples were incubated in the secondary antibodies (SP Table 1) for $1 \mathrm{~h}$ at room temperature. Unbound antibodies were removed in four changes of PBS /0.1\% Triton X-100 (15 min each) and nuclei were stained in 1:10000 dilution of $10.9 \mathrm{mM}$ DAPI (Invitrogen) for $30 \mathrm{~min}$. After the final round of washes $(3 \times 10 \mathrm{~min})$, the samples were coverslipped in SlowFade antifade medium (Invitrogen). Stacks of optical sections were taken using the Zeiss 880 confocal laser scanning microscope. Z-projections were generated in the Fiji image processing software and Imaris (Oxford Instruments).

\section{Generation of BAC-reporters}

The sox4-BAC was recombineered with different fluorescent reporters (SP Table 2) following the established protocol (Buckley and Ettensohn, 2019). The EL250 cells and the GFP recombination cassette were generous gifts from Dr. Buckley. The GFP coding sequence was 
replaced with either Kaede coding sequence or mCardinal coding sequence in the recombination cassette. Using the same protocol, we generated a sox2-Kaede BAC (SP Table 2). Embryos injected with recombineered BACs were observed at $2 \mathrm{dpf}, 4 \mathrm{dpf}$ and $7 \mathrm{dpf}$ to confirm the expression pattern recapitulating sox 2 or sox4.

\section{Microinjection of BACs}

BAC-reporters were injected into fertilized eggs at a final concentration of $10 \mathrm{ng} / \mu \mathrm{l}$ as previously described (Cheatle Jarvela and Hinman, 2014). For double lineage tracing an equivalent amount of sox2-Kaede BAC and sox4-Cardinal BAC were mixed at a final concentration of 10 $\mathrm{ng} / \mu \mathrm{l}$. Injected positive embryos were sorted under fluorescent stereo microscope at 24-48 hpf and then were kept in sea water at $15^{\circ} \mathrm{C}$ until future manipulations.

\section{Photo-Conversion of Kaede P. miniata cells}

Kaede is a photoconvertible fluorescent protein that changes irreversibly from green to red upon exposure to violet light (Ando et al., 2002). Photo-conversion of the Kaede was performed using an Andor Revolution XD spinning Disk confocal microscope emitting at $405 \mathrm{~nm}$ with 100\% laser power for $60-80 \mathrm{sec}$ with snapshots taken every $10 \mathrm{sec}$. After conversion transgenic embryos and larva were inspected for completion of conversion using the same microscope as quickly as possible to reduce the stress and transferred back to the plate with ASW.

\section{Live embryos/larva manipulation and Live imaging}

To trace cell fate we kept transgenic embryos and larvae individually in a small petri dish with ASW at $15^{\circ} \mathrm{C}$. Before imaging the animals were immobilized in $500 \mathrm{mM}$ high salt sea water for 1-2 min to remove the cilia, then mounted on the slides. Immediately after imaging, coverslip was carefully picked up and animals were transferred back to the dish. To increase survival rate the animals were manipulated as quickly as possible, the different laser power settings were used to minimize tissue damage in embryonic and larval stages. Regenerated larvae at different time points were imaged with consistent settings for comparison. Imaging was performed by using the Andor Revolution XD spinning Disk confocal microscope with Andor IQ3 system. Z-projections of stacks of optical sections were generated in the Fiji image software. 


\section{Establishing Kaede protein stability in embryos}

Generation and injection of kaede mRNA

Kaede PCR product was amplified from the plasmid (Addgene \#54726) for generating the template for capped mRNA synthesis (primers F: 5'- TAA TAC GAC TCA CTA TAG GGG TCG CCA CCA TGA GTC TGA T -3'; R: 5'-TTG CCG ATT TCG GCC TAT TGG -3') with mMESSAGE mMACHINE T7 transcription kit (ThermoFischer). Kaede mRNA was injected into the fertilized eggs at a final concentration of $300 \mathrm{ng} / \mu \mathrm{l}$. Kaede positive embryos were sorted under $488 \mathrm{~nm}$ fluorescent light at $15 \mathrm{hpf}$, then were kept in a plate with artificial sea water (ASW) at $15^{\circ} \mathrm{C}$ until live imaging. These embryos were starved prior to imaging to avoid fluorescent background from their algal stomach contents.

Generation of the conversion plot and the conversion rate plot

Photo-conversion was completed manually with Andor Revolution XD spinning Disk confocal microscope as described above. The time-lapse data were analyzed with Fiji. The pixel values (fluorescent intensity, or FI) of $488 \mathrm{~nm}$ and $560 \mathrm{~nm}$ channels within selected areas were measured at each time point. The background FI was subtracted to obtain the net FI which was plotted over time to generate the photo-conversion plot. The ratio of net FI $(560 \mathrm{~nm})$ over net FI $(488 \mathrm{~nm})$ was calculated and plotted over time to generate the conversion rate plot (SP File1).

Kaede stability - the fluorescence intensity curve

Twelve embryos injected with Kaede mRNA were photoconverted at $24 \mathrm{hpf}$ and were imaged everyday up to $12 \mathrm{dpf}$. Out of the 12 converted embryos, 6 survived the repetitive imaging session. The net FI of the $488 \mathrm{~nm}$ and $560 \mathrm{~nm}$ channels were collected and calculated following the steps described above. The net FI of both channels were plotted over time to generate the fluorescence intensity curve (SP File1).

Quantification of Green Sox4+ cells and statistical analyses

Quantification of green Sox4+ cells was conducted manually in larvae. Unhealthy, abnormal or dying larvae were not quantified. Quantification data of 5dpf larvae ( Kaede converted at 2dpf embryonic stage, or embryonic conversion) and 7dpf larvae (Kaede converted at 4dpf larval stage, or larval conversion) were then processed for statistical analyses using the website https://www.estimationstats.com/\#/. Two group comparison was performed using Delta's Cliff 
comparison. The confidence interval width was 95\%. Two side p-value was calculated with the Brunner-Munzel test. The Brunner-Munzel test was chosen because it did not require the assumption of equivariance of two groups. The probabilities of getting large values in both groups are equal. This test works on two independent samples, which may have different sizes.

The green Sox4+ cells at the regeneration leading edge were quantified manually in 7 larvae at $3 \mathrm{dpb}$ using Fiji. The data was compared to the $2 \mathrm{dpf}$ embryonic conversion data. The effect size was Cliff's delta and the mean of data. The confidence interval width was $95 \%$. Two side $p$-value was calculated with the Brunner-Munzel test. The data was compared to the $7 \mathrm{dpf}$ larval conversion data. Delta's cliff did not apply to these two groups. Instead, we compared the means of the two groups. The confidence interval width was $95 \%$. Two side $p$-value was calculated with the Mann Whitney test (SP File1).

\section{Quantification of Kaede+ cells and determination of colors}

Quantification of green, red and yellow Sox4+ cells was conducted manually in Z-stack images. The cellular area of each colored cell was compared to an adjacent background area with no Kaede signal to measure FI of $488 \mathrm{~nm}$ and $560 \mathrm{~nm}$ channels respectively. The $\mathrm{FI}$ in the background area was subtracted from the $\mathrm{FI}$ at each channel within the cellular area to generate the net $\mathrm{FI}$ of the colored cell at $488 \mathrm{~nm}$ and $560 \mathrm{~nm}$ channels. We then calculated the ratio of net FI $(560 \mathrm{~nm})$ over net FI $(488 \mathrm{~nm})$ for each cell. The three colored groups were defined as follows: if the net FI ratio of $560 \mathrm{~nm} / 488 \mathrm{~nm}>5$, the cell is considered as a red cell; if the ratio is between $1 / 5$ and 5 , the cell is considered as a yellow cell; if the ratio of $560 \mathrm{~nm} / 488 \mathrm{~nm}<1 / 5$, the cell is considered as a green cell.

Inhibition of cell division

To inhibit cell division, we used aphidicolin (Sigma A0781) at a dosage of $8.3 \mu \mathrm{g} / \mathrm{g}(25 \mu \mathrm{M})$ in sea water. The first treatment was done immediately post-injury, followed by 2 more drug changes every 24 hours. Control animals received 0.08\% DMSO (vehicle) incubation. The aphidicolin treatment, therefore, covered the phases of regeneration, and preceded the first observed sox 2 and sox 4 expression by at least one day. These treatment parameters were established after a series of pilot experiments using two drug concentrations ( $25 \mathrm{uM}, 50 \mathrm{uM}$ ), followed by 1 hour incubation in 15 uM EdU, which was detected by standard protocol 
bioRxiv preprint doi: https://doi.org/10.1101/2021.08.07.455526; this version posted August 8, 2021. The copyright holder for this preprint (which was not certified by peer review) is the author/funder. All rights reserved. No reuse allowed without permission.

(invitrogen C10637). To elucidate sox2+, sox4+ cells fate without cell division the fertilized eggs were injected with sox2, sox4 Bacs, 1week old larvae were bisected, photoconverted, incubated in aphidicolin solution for 3 days and then imaged. 


\section{Acknowledgements}

The authors are grateful to Dr. Buckley for the assistance in BACs recombineering and Dr Cheryl Telmer, Dr Andrew Wolff, and Jonathan Andrade for helpful comments on the manuscript. The work was supported by NSF. IOS 1557431, NIH 1R24OD023046 and DSF Charitable Foundation. 


\section{Bibliography}

Ando, R., Hama, H., Yamamoto-Hino, M., Mizuno, H., Miyawaki, A., 2002. An optical marker based on the UV-induced green-to-red photoconversion of a fluorescent protein. Proc Natl Acad Sci USA 99, 12651-12656. doi:10.1073/pnas.202320599

Angerer, L.M., Yaguchi, S., Angerer, R.C., Burke, R.D., 2011. The evolution of nervous system patterning: insights from sea urchin development. Development 138, 3613-3623. doi:10.1242/dev.058172

Arnone, M.I., Bogarad, L.D., Collazo, A., Kirchhamer, C.V., Cameron, R.A., Rast, J.P., Gregorians, A., Davidson, E.H., 1997. Green Fluorescent Protein in the sea urchin: new experimental approaches to transcriptional regulatory analysis in embryos and larvae. Development 124, 4649-4659.

Ben Khadra, Y., Sugni, M., Ferrario, C., Bonasoro, F., Oliveri, P., Martinez, P., Candia Carnevali, M.D., 2018. Regeneration in stellate echinoderms: crinoidea, asteroidea and ophiuroidea. Results Probl. Cell Differ. 65, 285-320. doi:10.1007/978-3-319-92486-1_14

Ben Khadra, Y., Sugni, M., Ferrario, C., Bonasoro, F., Varela Coelho, A., Martinez, P., Candia Carnevali, M.D., 2017. An integrated view of asteroid regeneration: tissues, cells and molecules. Cell Tissue Res. 370, 13-28. doi:10.1007/s00441-017-2589-9

Buckley, K.M., Ettensohn, C.A., 2019. Techniques for analyzing gene expression using BAC-based reporter constructs. Methods Cell Biol. 151, 197-218. doi:10.1016/bs.mcb.2019.01.004

Burke, R.D., Osborne, L., Wang, D., Murabe, N., Yaguchi, S., Nakajima, Y., 2006. Neuron-specific expression of a synaptotagmin gene in the sea urchin Strongylocentrotus purpuratus. J. Comp. Neurol. 496, 244-251. doi:10.1002/cne.20939

Carter, H.F., Thompson, J.R., Elphick, M.R., Oliveri, P., 2021. The development and neuronal complexity of bipinnaria larvae of the sea star Asterias rubens. Integr. Comp. Biol. doi:10.1093/icb/icab103

Cary, G.A., Cameron, R.A., Hinman, V.F., 2018. Echinobase: tools for echinoderm genome analyses. Methods Mol. Biol. 1757, 349-369. doi:10.1007/978-1-4939-7737-6_12

Cary, G.A., Cameron, R.A., Hinman, V.F., 2019a. Genomic resources for the study of echinoderm development and evolution. Methods Cell Biol. 151, 65-88. doi:10.1016/bs.mcb.2018.11.019

Cary, G.A., Cheatle Jarvela, A.M., Francolini, R.D., Hinman, V.F., 2017. Genome-wide use of high- and low-affinity Tbrain transcription factor binding sites during echinoderm development. Proc Natl Acad Sci USA 114, 5854-5861. doi:10.1073/pnas.1610611114

Cary, G.A., Hinman, V.F., 2017. Echinoderm development and evolution in the post-genomic era. Dev. Biol. 427, 203-211. doi:10.1016/j.ydbio.2017.02.003

Cary, G.A., McCauley, B.S., Zueva, O., Pattinato, J., Longabaugh, W., Hinman, V., 2020. Systematic comparison of developmental GRNs explains how novelty is incorporated in early development. BioRxiv. doi:10.1101/2020.08.07.231464

Cary, G.A., Wolff, A., Zueva, O., Pattinato, J., Hinman, V.F., 2019b. Analysis of sea star larval regeneration reveals conserved processes of whole-body regeneration across the metazoa. 
BMC Biol. 17, 16. doi:10.1186/s12915-019-0633-9

Cheatle Jarvela, A.M., Brubaker, L., Vedenko, A., Gupta, A., Armitage, B.A., Bulyk, M.L., Hinman, V.F., 2014. Modular evolution of DNA-binding preference of a Tbrain transcription factor provides a mechanism for modifying gene regulatory networks. Mol. Biol. Evol. 31, 2672-2688. doi:10.1093/molbev/msu213

Cheatle Jarvela, A.M., Hinman, V., 2014. A method for microinjection of Patiria miniata zygotes. J. Vis. Exp. e51913. doi:10.3791/51913

Cheatle Jarvela, A.M., Yankura, K.A., Hinman, V.F., 2016. A gene regulatory network for apical organ neurogenesis and its spatial control in sea star embryos. Development 143, 4214-4223. doi:10.1242/dev.134999

Dupont, S., Thorndyke, M., 2007. Bridging the regeneration gap: insights from echinoderm models. Nat. Rev. Genet. 8. doi:10.1038/nrg1923-c1

Elia, L., Selvakumaraswamy, P., Byrne, M., 2009. Nervous system development in feeding and nonfeeding asteroid larvae and the early juvenile. Biol. Bull. 216, 322-334. doi:10.1086/BBLv216n3p322

Feng, R., Wen, J., 2015. Overview of the roles of Sox2 in stem cell and development. Biol. Chem. 396, 883-891. doi:10.1515/hsz-2014-0317

Ferrario, C., Sugni, M., Somorjai, I.M.L., Ballarin, L., 2020. Beyond adult stem cells: dedifferentiation as a unifying mechanism underlying regeneration in invertebrate deuterostomes. Front. Cell Dev. Biol. 8, 587320. doi:10.3389/fcell.2020.587320

García-Arrarás, J.E., Lázaro-Peña, M.I., Díaz-Balzac, C.A., 2018. Holothurians as a model system to study regeneration. Results Probl. Cell Differ. 65, 255-283. doi:10.1007/978-3-319-92486-1_13

Gehrke, A.R., Neverett, E., Luo, Y.-J., Brandt, A., Ricci, L., Hulett, R.E., Gompers, A., Ruby, J.G., Rokhsar, D.S., Reddien, P.W., Srivastava, M., 2019. Acoel genome reveals the regulatory landscape of whole-body regeneration. Science 363. doi:10.1126/science.aau6173

Gerber, T., Murawala, P., Knapp, D., Masselink, W., Schuez, M., Hermann, S., Gac-Santel, M., Nowoshilow, S., Kageyama, J., Khattak, S., Currie, J.D., Camp, J.G., Tanaka, E.M., Treutlein, B., 2018. Single-cell analysis uncovers convergence of cell identities during axolotl limb regeneration. Science 362. doi:10.1126/science.aaq0681

Gildor, T., Cary, G.A., Lalzar, M., Hinman, V.F., Ben-Tabou de-Leon, S., 2019. Developmental transcriptomes of the sea star, Patiria miniata, illuminate how gene expression changes with evolutionary distance. Sci. Rep. 9, 16201. doi:10.1038/s41598-019-52577-9

Hernroth, B., Farahani, F., Brunborg, G., Dupont, S., Dejmek, A., Sköld, H.N., 2010. Possibility of mixed progenitor cells in sea star arm regeneration. J. Exp. Zool. B Mol. Dev. Evol. 314, 457-468. doi:10.1002/jez.b.21352

Hinman, V.F., Burke, R.D., 2018. Embryonic neurogenesis in echinoderms. Wiley Interdiscip. Rev. Dev. Biol. 7, e316. doi:10.1002/wdev.316

Hinman, V.F., Nguyen, A.T., Davidson, E.H., 2003. Expression and function of a starfish Otx ortholog, AmOtx: a conserved role for Otx proteins in endoderm development that predates divergence of the eleutherozoa. Mech. Dev. 120, 1165-1176.

doi:10.1016/j.mod.2003.08.002 
Joven, A., Simon, A., 2018. Homeostatic and regenerative neurogenesis in salamanders. Prog. Neurobiol. 170, 81-98. doi:10.1016/j.pneurobio.2018.04.006

Kasahara, M., Kobayashi, C., Yamanaka, A., Kitazawa, C., 2019. Regeneration of the cell mass in larvae of temnopleurid sea urchins. J. Exp. Zool. B Mol. Dev. Evol. 332, 245-257. doi:10.1002/jez.b.22899

Katow, H., Elia, L., Byrne, M., 2009. Development of nervous systems to metamorphosis in feeding and non-feeding echinoid larvae, the transition from bilateral to radial symmetry. Dev. Genes Evol. 219, 67-77. doi:10.1007/s00427-008-0266-4

Kondo, M., Akasaka, K., 2010. Regeneration in crinoids. Dev. Growth Differ. 52, 57-68. doi:10.1111/j.1440-169X.2009.01159.x

Kragl, M., Knapp, D., Nacu, E., Khattak, S., Maden, M., Epperlein, H.H., Tanaka, E.M., 2009. Cells keep a memory of their tissue origin during axolotl limb regeneration. Nature 460, 60-65. doi:10.1038/nature08152

Mashanov, V., Akiona, J., Khoury, M., Ferrier, J., Reid, R., Machado, D.J., Zueva, O., Janies, D., 2020. Active Notch signaling is required for arm regeneration in a brittle star. PLoS ONE 15, e0232981. doi:10.1371/journal.pone.0232981

Mashanov, V., Zueva, O., 2019. Radial glia in echinoderms. Dev. Neurobiol. 79, 396-405. doi:10.1002/dneu.22659

Mashanov, V.S., Zueva, O.R., García-Arrarás, J.E., 2015a. Expression of pluripotency factors in echinoderm regeneration. Cell Tissue Res. 359, 521-536. doi:10.1007/s00441-014-2040-4

Mashanov, V.S., Zueva, O.R., García-Arrarás, J.E., 2015b. Heterogeneous generation of new cells in the adult echinoderm nervous system. Front. Neuroanat. 9, 123. doi:10.3389/fnana.2015.00123

Mashanov, V.S., Zueva, O.R., García-Arrarás, J.E., 2017. Inhibition of cell proliferation does not slow down echinoderm neural regeneration. Front. Zool. 14, 12. doi:10.1186/s12983-017-0196-y

McCauley, B.S., Akyar, E., Filliger, L., Hinman, V.F., 2013. Expression of wnt and frizzled genes during early sea star development. Gene Expr. Patterns 13, 437-444. doi:10.1016/j.gep.2013.07.007

Murabe, N., Hatoyama, H., Hase, S., Komatsu, M., Burke, R.D., Kaneko, H., Nakajima, Y., 2008. Neural architecture of the brachiolaria larva of the starfish, Asterina pectinifera. J. Comp. Neurol. 509, 271-282. doi:10.1002/cne.21742

Nakajima, Y., Kaneko, H., Murray, G., Burke, R.D., 2004. Divergent patterns of neural development in larval echinoids and asteroids. Evol. Dev. 6, 95-104. doi:10.1111/j.1525-142x.2004.04011.x

Nishioka, D., Balczon, R., Schatten, G., 1984. Relationships between DNA synthesis and mitotic events in fertilized sea urchin eggs: aphidicolin inhibits DNA synthesis, nuclear breakdown and proliferation of microtubule organizing centers, but not cycles of microtubule assembly. Cell Biol. Int. Rep. 8, 337-346. doi:10.1016/0309-1651(84)90161-9

Oulhen, N., Heyland, A., Carrier, T.J., Zazueta-Novoa, V., Fresques, T., Laird, J., Onorato, T.M., Janies, D., Wessel, G., 2016. Regeneration in bipinnaria larvae of the bat star Patiria miniata induces rapid and broad new gene expression. Mech. Dev. 142, 10-21. doi:10.1016/j.mod.2016.08.003 
Piovani, L., Czarkwiani, A., Ferrario, C., Sugni, M., Oliveri, P., 2021. Ultrastructural and molecular analysis of the origin and differentiation of cells mediating brittle star skeletal regeneration. BMC Biol. 19, 9. doi:10.1186/s12915-020-00937-7

Range, R.C., Angerer, R.C., Angerer, L.M., 2013. Integration of canonical and noncanonical Wnt signaling pathways patterns the neuroectoderm along the anterior-posterior axis of sea urchin embryos. PLoS Biol. 11, e1001467. doi:10.1371/journal.pbio.1001467

Reddien, P.W., 2019. The cells of regeneration. Science 365, 314-316. doi:10.1126/science.aay3660

Reinardy, H.C., Emerson, C.E., Manley, J.M., Bodnar, A.G., 2015. Tissue regeneration and biomineralization in sea urchins: role of Notch signaling and presence of stem cell markers. PLoS ONE 10, e0133860. doi:10.1371/journal.pone.0133860

Rodriguez, A.M., Kang, J., 2020. Regeneration enhancers: Starting a journey to unravel regulatory events in tissue regeneration. Semin. Cell Dev. Biol. 97, 47-54. doi:10.1016/j.semcdb.2019.04.003

Sánchez Alvarado, A., 2006. Planarian regeneration: its end is its beginning. Cell 124, 241-245. doi:10.1016/j.cell.2006.01.012

Soufi, A., Garcia, M.F., Jaroszewicz, A., Osman, N., Pellegrini, M., Zaret, K.S., 2015. Pioneer transcription factors target partial DNA motifs on nucleosomes to initiate reprogramming. Cell 161, 555-568. doi:10.1016/j.cell.2015.03.017

Takahashi, K., Yamanaka, S., 2006. Induction of pluripotent stem cells from mouse embryonic and adult fibroblast cultures by defined factors. Cell 126, 663-676. doi:10.1016/j.cell.2006.07.024

Tanaka, E.M., Reddien, P.W., 2011. The cellular basis for animal regeneration. Dev. Cell 21, 172-185. doi:10.1016/j.devcel.2011.06.016

Vickery, M.C., Vickery, M.S., Amsler, C.D., McClintock, J.B., 2001. Regeneration in echinoderm larvae. Microsc. Res. Tech. 55, 464-473. doi:10.1002/jemt.1191

Vickery, M.S., Vickery, M.C.L., McClintock, J.B., 2002. Morphogenesis and organogenesis in the regenerating planktotrophic larvae of asteroids and echinoids. Biol. Bull. 203, 121-133. doi:10.2307/1543381

Wolff, A., Hinman, V., 2021. The Use of Larval Sea Stars and Sea Urchins in the Discovery of Shared Mechanisms of Metazoan Whole-Body Regeneration. genes 12, 1063. doi:10.3390/genes12071063

Yankura, K.A., Koechlein, C.S., Cryan, A.F., Cheatle, A., Hinman, V.F., 2013. Gene regulatory network for neurogenesis in a sea star embryo connects broad neural specification and localized patterning. Proc Natl Acad Sci USA 110, 8591-8596. doi:10.1073/pnas.1220903110

Yankura, K.A., Martik, M.L., Jennings, C.K., Hinman, V.F., 2010. Uncoupling of complex regulatory patterning during evolution of larval development in echinoderms. BMC Biol. 8, 143. doi:10.1186/1741-7007-8-143

Zhang, F., Ferretti, P., Clarke, J.D.W., 2003. Recruitment of postmitotic neurons into the regenerating spinal cord of urodeles. Dev. Dyn. 226, 341-348. doi:10.1002/dvdy.10230

Zhu, S.J., Pearson, B.J., 2016. (Neo)blast from the past: new insights into planarian stem cell lineages. Curr. Opin. Genet. Dev. 40, 74-80. doi:10.1016/j.gde.2016.06.007 


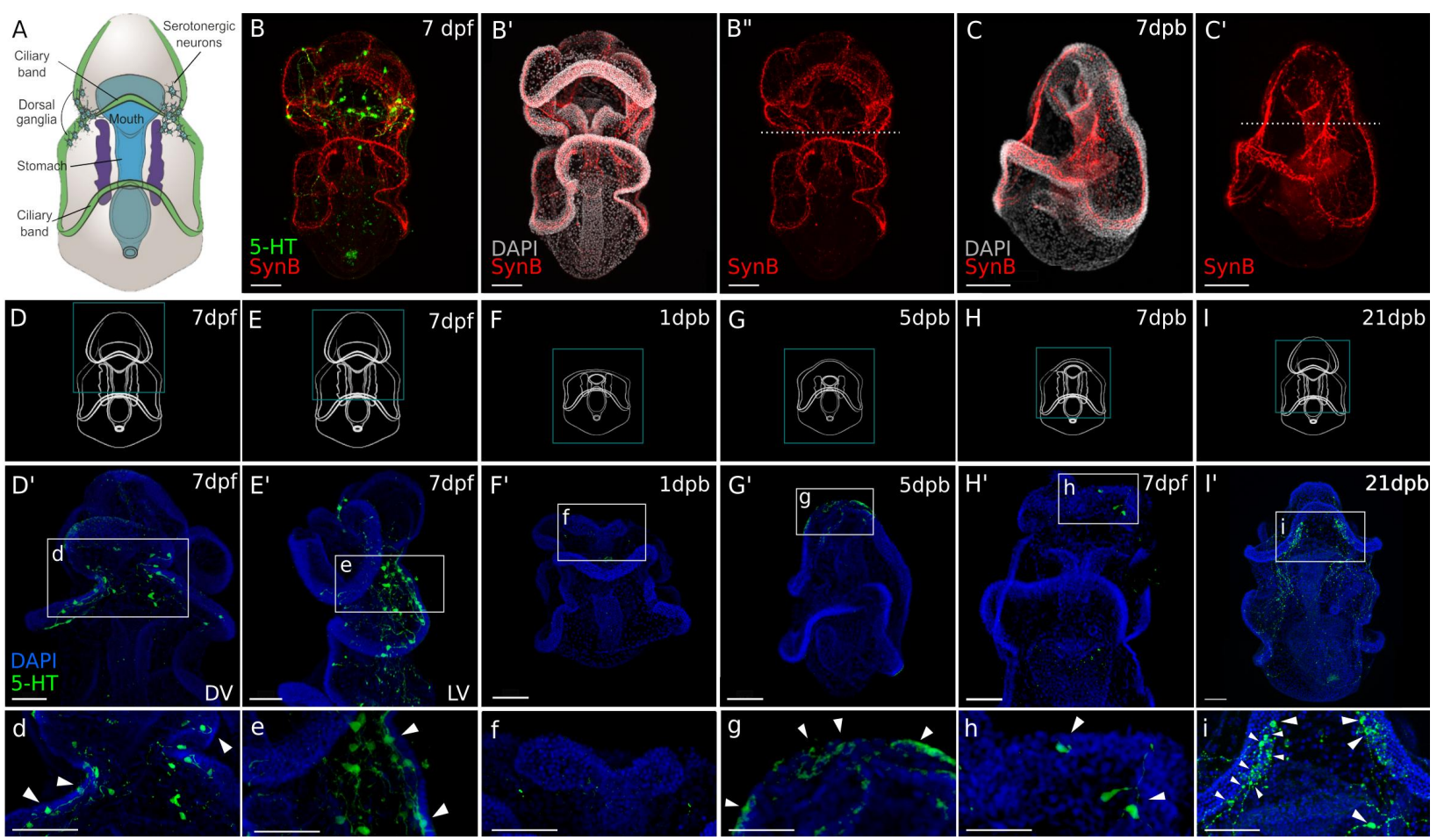

Fig 1. Regeneration of the sea star larval nervous system.

(A) A schematic of a 7 day old Patiria miniata larva. (B-B") Immunostaining with anti-synaptotagmin B (SynB; red) and anti-serotonin (5-HT; green) shows the larval nervous system organisation. Serotonergic neurons are distributed along the pre-oral ciliary band, post-oral ciliary bands and around the mouth. Larvae are bisected beneath the lip of the mouth shown by the dotted line (B" and C'). (C-C") A latero-ventral view of regenerated larva at 7 days post bisection, the nervous system staining with Syn $B$. As bisection was performed at the site represented with the white dashed line; Above the dashed line $\left(C^{\prime}\right)$ is the regenerated anterior tissue with reformed pre-oral ciliary band and the mouth. (D-I) Schematics of larvae at the normal (uncut) and regenerated stages corresponding to immunostaining with anti-serotonin images in ( $\left.D^{\prime}-I^{\prime}\right)$ and (d-i). (d-i) The expanded view of the region highlighted with the dashed-line box in ( $\left.D^{\prime}-I^{\prime}\right)$. ( $\left.D^{\prime}\right)$ The serotonergic neurons are located bilaterally in uncut larvae, on the dorsal side (right) as shown in lateral view in (E'). (d-e) Neural bodies are embedded in the ectoderm, and project long axonal processes typical of this neural type. ( $\left.F^{\prime}-f\right)$ Bisection removes the serotonergic neurons. (G') By $5 \mathrm{dpb}$, serotonergic neurons are detected at the regeneration leading edge with emerging neural morphology as shown in $(\mathrm{g})$. ( $\left.\mathrm{H}^{\prime}\right)$ By 7 $\mathrm{dpb}$, regenerated serotonergic neurons with mature neural morphology $(\mathrm{h})$ are located at the lateral side of the regenerated anterior. (l'-i) Regenerated serotonergic neurons are bilaterally located to reform the dorsal ganglia by $21 \mathrm{dpb}$. Arrowheads highlight the serotonergic neurons. Dpf: day-post fertilization; dpb: day-post bisection. DV: dorsal view. LV: lateral view. Scale bar: $50 \mu \mathrm{m}$. 


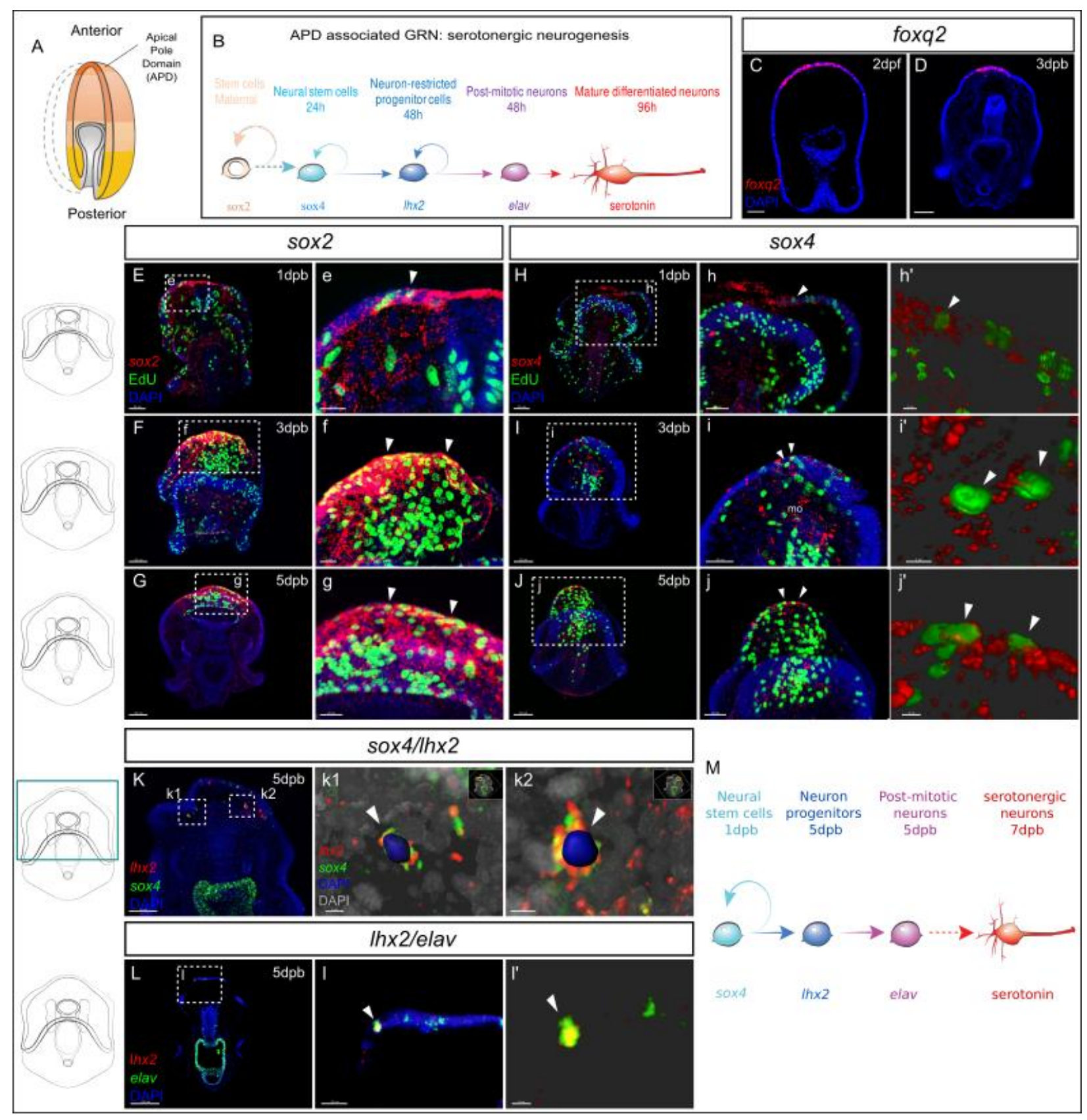

Fig 2. Recapitulation of embryonic neural gene expression during regeneration. $(A)$ in normal development, the embryonic apical pole domain (ADP) gives rise to serotonergic neurons via the ADP-associated neurogenesis pathway illustrated in (B). (C-D) Fluorescent in situ hybridization (FISH) of ADP marker gene foxq2 in embryos (C) and in the leading edge of the regenerating larvae at $3 \mathrm{dpb}(\mathrm{D})$. (E-j') EdU labeled and FISH (EdU-FISH) results show that sox2 and sox4 are expressed in proliferative cells at the regeneration leading edge. (E-G) EdU-FISH of gene sox2. (e-g) expanded view of the boxed area in (E-G). (E) Upon bisection, sox2+ cells are highly concentrated at the 
wound site and later in (F-G) at the regeneration leading edge. Throughout the time-course, some sox2+ cells undergo cell cycling (e-g). (H-J) EdU-FISH of sox4. (h-j) Expanded view of the boxed area in $(\mathrm{H}-\mathrm{J})$. $(\mathrm{H})$ Upon bisection, sox4+ cells are detected at the leading regenerating edge and later in $(\mathrm{I}-\mathrm{J})$ at the regeneration leading edge including the mouth. Throughout the time-course, some sox4+ cells undergo cell division (h-j). ( $h$ '-j') 3D Imaris generated projection of EdU+ sox4+ cells highlighted in $(\mathrm{h}-\mathrm{j})$, indicated by white arrowheads. This shows clear double detection of EdU and sox4: the EdU+ nucleus is surrounded by sox4 signals. (K-i') Double fluorescent in situ hybridization (FISH) shows the recapitulation of APD gene expression trajectory. (K) In $5 \mathrm{dpb}$ larvae, sox 4 and $I h \times 2$ are co-expressed in cells at the lateral regeneration leading edge. Scale bar: $50 \mu \mathrm{m}$. (k1'-k2') Imaris 3D reconstructed view of boxed areas k1 and $\mathrm{k} 2$. In the highlighted cells (arrowheads), nucleus labeled with DAPI is surrounded by both $I h \times 2$ and sox4 signals, indicating co-expression in the same cell. Scale bar in (c1): $5 \mu \mathrm{m}$; (c2): $7 \mu \mathrm{m}$. (L) In $5 \mathrm{dpb}$ larvae, Ihx2 and elav are co-expressed in cells at the lateral regeneration leading edge, scale bar: $100 \mu \mathrm{m}$. This is amplified in (I). (I') shows the 3D reconstructed view of the cell marked by arrowheads in (I). (M) A proposed Model for the regeneration of neurons in sea star larvae. Dpb: day-post-bisection. Scale bar in (E-K): $50 \mu \mathrm{m}$; (L): $100 \mu \mathrm{m}$; (e-i,I): $20 \mu \mathrm{m}$; (j): $30 \mu \mathrm{m}$; (h'-j',k1 and l'): $5 \mu \mathrm{m}$; (k2): 7 $\mu \mathrm{m}$. Dpf: day-post fertilization; dpb: day-post bisection; mo, mouth. 


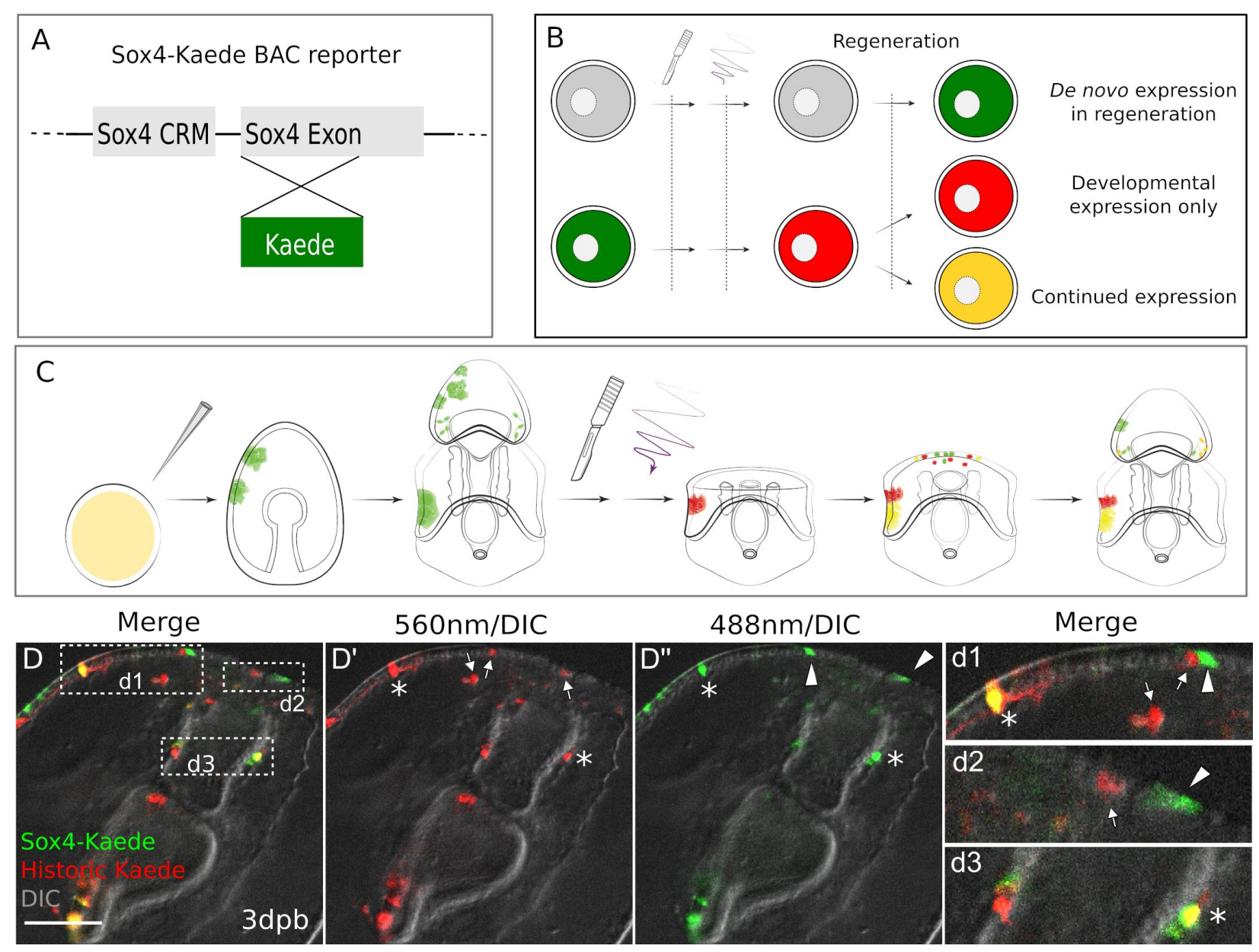

Fig 3. Existing and de novo Sox4+ lineages induced by wounding (A) The design of Sox4:Kaede BAC construct. (B-C) Design of photo-conversion experiment. Sea star zygotes are injected with the Sox4-Kaede BAC. Injected embryos are incubated till larvae for bisection. Photo-conversion is immediately performed on bisected posterior segments. After regenerating for $3 \mathrm{dpb}$, larvae are observed. (D) In Sox4-Kaede transgenic regenerating larvae, there are multiple sources of Sox4+ cells at the regeneration leading edge. Some Sox4+ cells are derived from the yellow, larval Sox4 lineage (marked by asterisks). Some Sox4+ cells are red only cells that no longer express Kaede (arrows). There are also green-only Sox4+ cells that are newly specified upon decapitation (arrowheads). The boxed areas in the regeneration leading edge are amplified in (d1), (d2) and (d3). Scale bar in (D): $50 \mu \mathrm{m}$. CRM: Cis regulatory modules 

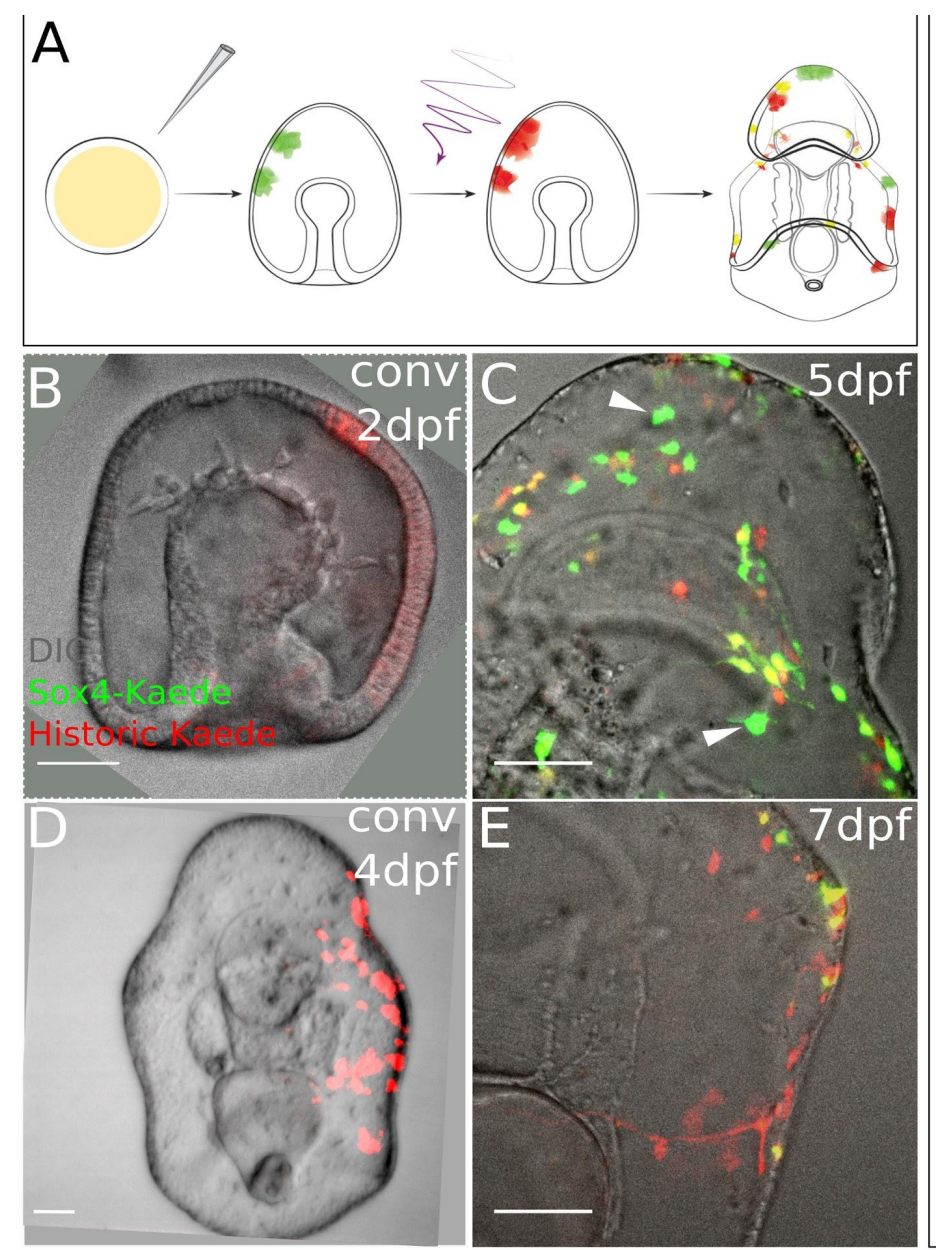

F Comparison of specification between embryos, larvae and regenerates
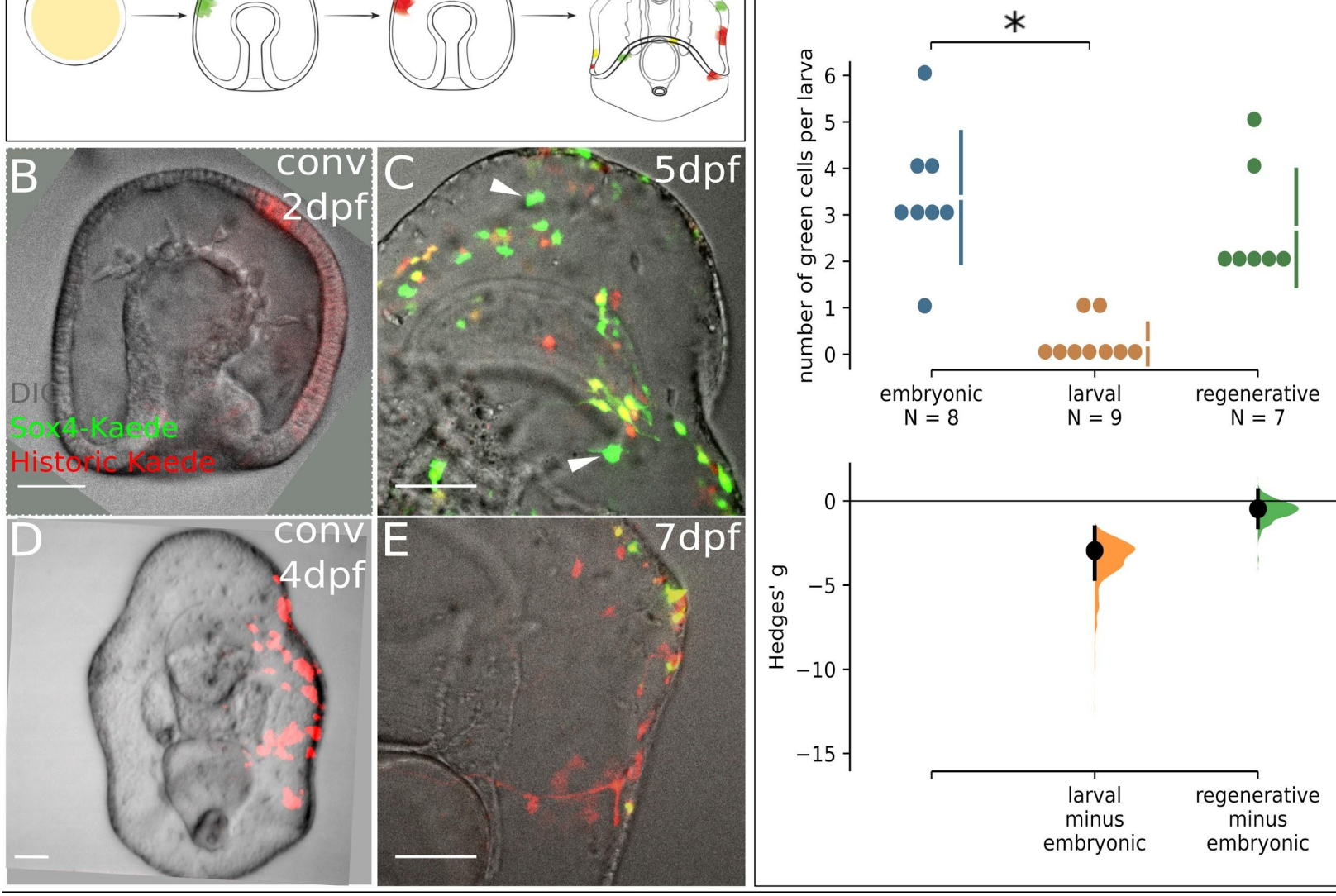

Fig 4. Specification of new Sox4+ cells ends at the larval stage and resumes in regeneration.

(A) A schematic for the experimental plan to determine the source of developmental larval Sox4+ cell lineage. (B) Embryo injected with Sox4-Kaede BAC is converted at 2 days post fertilization (dpf). Red Kaede localization therefore marks all labeled Sox4+ cells. (C) By $5 \mathrm{dpf}$ there are several newly specified, green Sox4+ cells indicated by arrowheads. However, (D) when converted at $4 \mathrm{dpf}$ (larval stage), only yellow cells and red cells are observed 3 days later as shown in (E), indicating no specification of Sox4+ cell occurs in the larva. (F) Quantification of Sox4 specification in embryos, larvae and regeneration. Sox $4+$ cell specification event is close to 0 at by $4 \mathrm{dpf}$, significantly decreased compared to the embryonic (2dpf) state. Specification of Sox4+ cells is restored in regenerating larvae. Scale bar in (B-E): $50 \mu \mathrm{m}$. dpf: day-post-fertilization. 


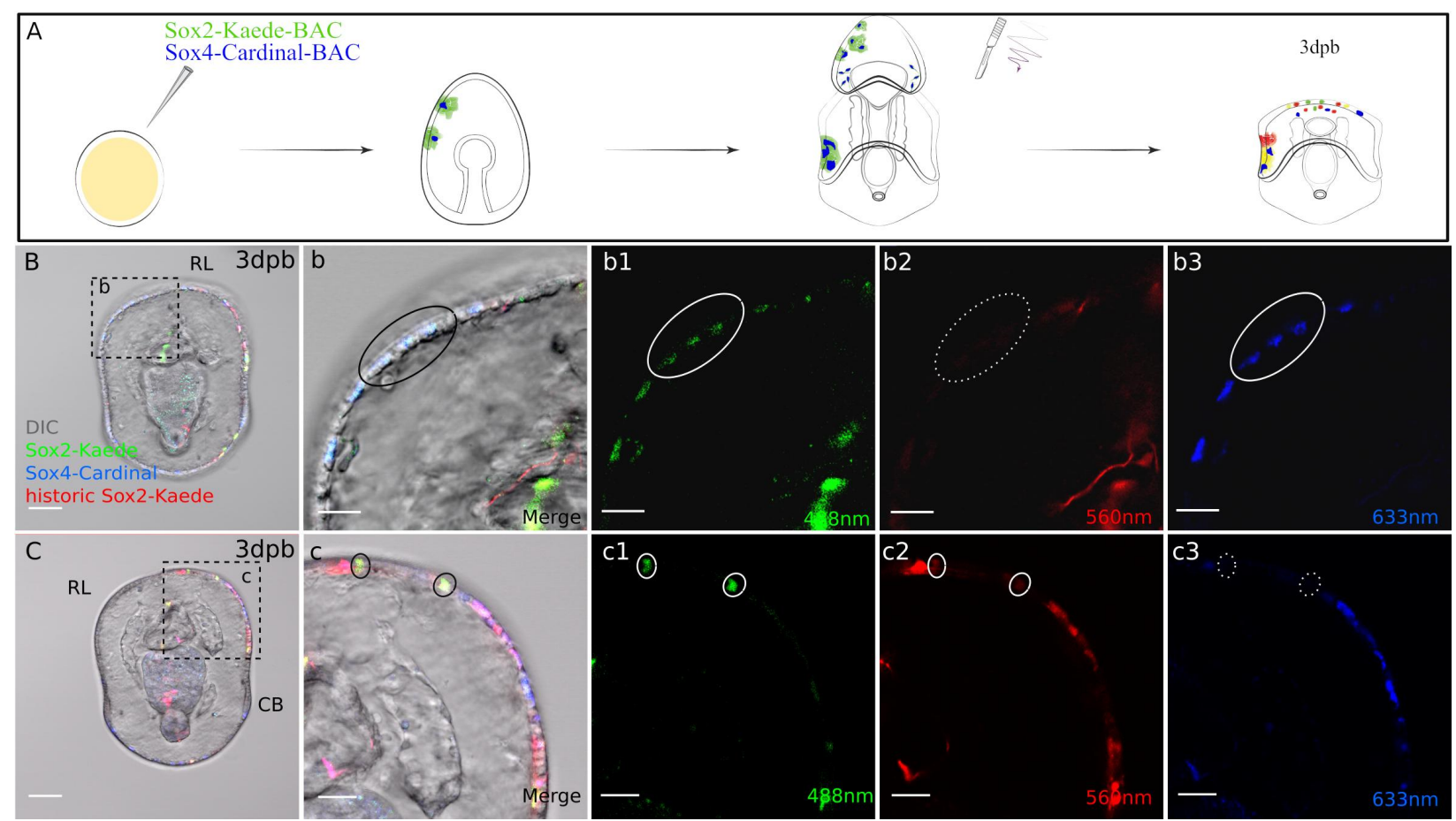

Fig 5. Sox4+ cells are specified from Sox2+ cells at the regeneration leading edge. (A) Schematic representation of the experimental design. Two BACs: sox2-Kaede and sox4-Cardinal were co-injected. 7 days old transgenic larvae were bisected, Kaede protein was photoconverted immediately following bisection, then regenerated larvae were analysed at three days later. (B-c3) Sox4+ cells (blue) at the regeneration leading edge overlap with de novo specified Sox2+ cells (green) (shown circled) as well as existing (red) sox2 cells. Boxed areas in B, C are expanded as (b-b3) and (c-c3). Sox2+ cells (green and red) do not always overlap with sox4+ cells (blue). E.g. with (c1) green and (c2) red Kaede (white solid circle), (c3) but not Cardinal (white dotted circle). Scale bar in (B-C): $50 \mu \mathrm{m}$; (b-b3, c-c3): $20 \mu \mathrm{m}$; (d-d3). RL, regeneration leading edge; CB, ciliary band. Dpb: day-post-bisection. Sox2: Kaede (red, yellow, green) and Sox4: Cardinal (far red, false colored to blue). 


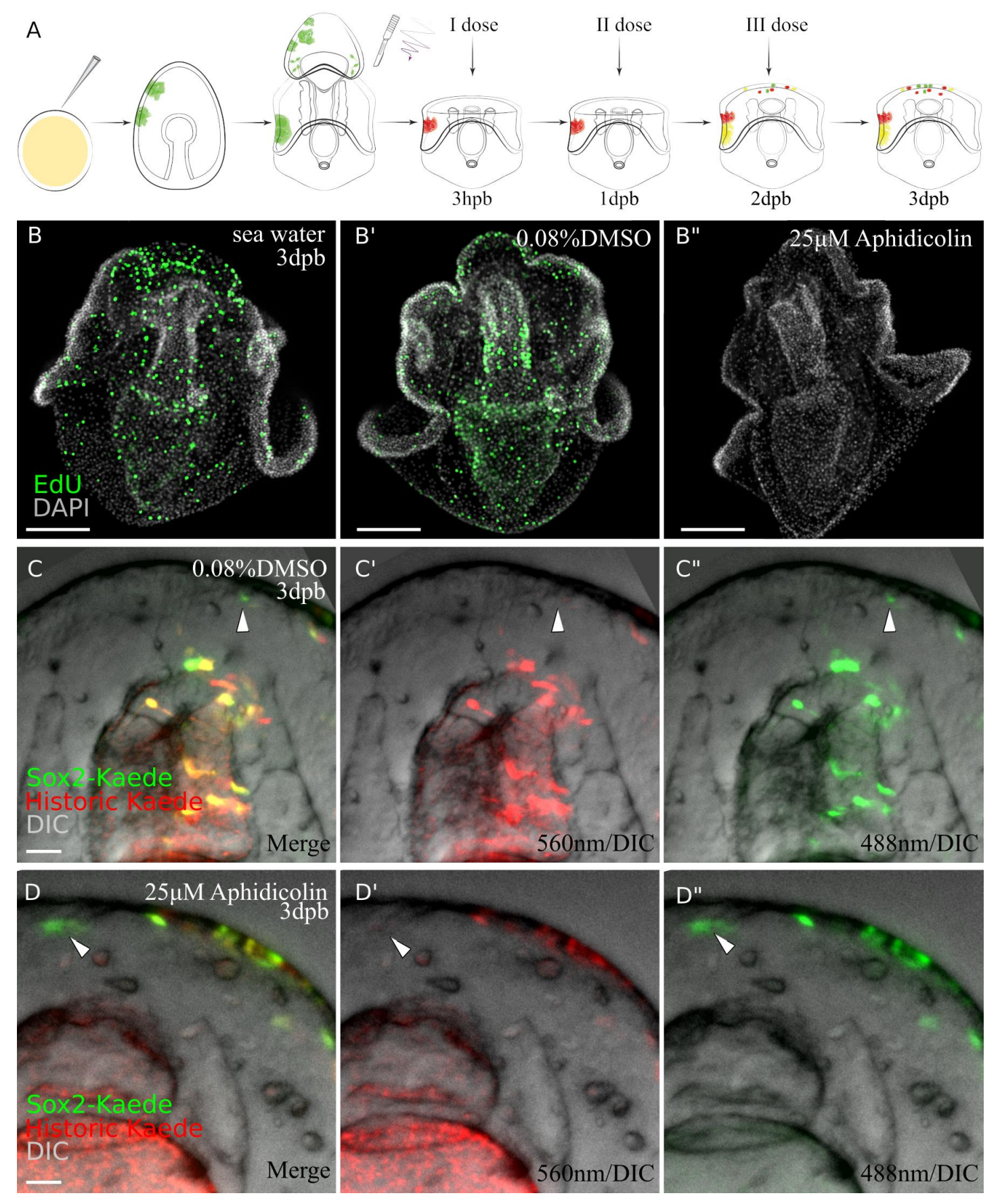

Fig 6. Sox2+ cells fate specification (continued or de novo expression) does not depend on entering into the cell cycle during the early stage (upto $3 \mathrm{dpb}$ ) of regeneration.

A) Schematic representation of the experimental design. Sox2-Kaede transgenic larvae were bisected and photoconverted. The first dose of $25 \mu \mathrm{M}$ aphidicolin or vehicle $(0.08 \%$ DMSO) were applied immediately after bisection, changed every $24 \mathrm{~h}$ until $3 \mathrm{dpb}$ then the regenerated larvae were analysed. (B-B") To monitor the effect of aphidicolin on 
DNA synthesis, we used an EdU cell proliferation assay. 3dpb larvae in aphidicolin, DMSO or sea water solutions were incubated in $15 \mu \mathrm{M}$ EdU for $1 \mathrm{~h}$. (C-D) Sox2-Kaede cell specification by $3 \mathrm{dpb}$ under aphidicolin (D-D") or vehicle (C-C") treatment. Scale bar in B-B", C-D. Dpb: day-post-bisection. Arrowheads highlight de novo Kaede FP. 